\title{
Predictors of imminent risk of fracture in Medicare-enrolled men and women
}

\author{
Akeem A. Yusuf ${ }^{1} \cdot$ Yan Hu$^{2} \cdot$ David Chandler ${ }^{1} \cdot$ Daria B. Crittenden ${ }^{1} \cdot$ Richard L. Barron ${ }^{1}$ \\ Received: 16 August 2019 / Accepted: 7 July 2020 / Published online: 3 August 2020 \\ (C) The Author(s) 2020
}

\begin{abstract}
Summary Advancing age, female sex, recent prior fracture and falls, and specific comorbidities and medications contribute to imminent (within 1-2 years) risk of fracture in Medicare enrollees. Clinician awareness of these risk factors and their dynamic nature may lead to improved osteoporosis care for elderly patients.

Purpose The burden of osteoporotic fracture disproportionately affects the elderly. Growing awareness that fracture risk can change substantially over time underscores the need to understand risk factors for imminent (within 1-2 years) fracture. This study assessed predictors of imminent risk of fracture in the US Medicare population.

Methods Administrative claims data from a random sample of Medicare beneficiaries were analyzed for patients aged $\geq 67$ years on January 1, 2011 (index date), with continuous coverage between January 1, 2009 and March 31, 2011, excluding patients with non-melanoma cancer or Paget's disease. Incident osteoporotic fractures were identified during 12 and 24 months post-index. Potential predictors were age, sex, race, history of fracture, history of falls, presence of osteoporosis, cardiovascular diseases, chronic obstructive pulmonary disorder (COPD), mood/anxiety disorders, polyinflammatory conditions, difficulty walking, use of durable medical equipment, ambulance/life support, and pre-index use of osteoporosis medications, steroids, or central nervous system medications. Cox proportional hazards models were used to evaluate predictors of fracture risk in the two follow-up intervals.

Results Among 1,780,451 individuals included (mean age 77.7 years, $66 \%$ female), $8.3 \%$ had prior fracture and $6.1 \%$ had a history of falls. During the 12- and 24-month follow-up periods, 3.0\% and 5.4\% of patients had an incident osteoporotic fracture, respectively. Imminent risk of fracture increased with older age (double/triple), female sex $(>80 \%)$, recent prior fracture (> double) and falls, and specific comorbidities and medications.

Conclusions Demographics and factors including fall/fracture history, comorbidities, and medications contribute to imminent risk of fracture in elderly patients.
\end{abstract}

Keywords Imminent risk $\cdot$ Near-term risk $\cdot$ Fracture $\cdot$ Osteoporosis $\cdot$ Medicare

\section{Introduction}

The risk of osteoporotic fracture increases with age, and the direct cost of treating osteoporosis-related fractures is

Electronic supplementary material The online version of this article (https://doi.org/10.1007/s11657-020-00784-7) contains supplementary material, which is available to authorized users.

David Chandler

dchandle@amgen.com

1 Amgen Inc., Thousand Oaks, CA, USA

2 Boston Scientific Corporation, Arden Hills, MN, USA expected to increase substantially as the number of incident fractures increases, especially in more economically developed countries [1-3]. In both private (commercial) and public (Medicaid, Medicare) health plans in the United States (US), patients with osteoporosis-related fracture have been shown to have higher medical costs than individuals without fractures $[4,5]$. Although osteoporosis patients may range in age, the literature suggests that burden of osteoporosis is concentrated among the elderly, in terms of both fracture incidence and fracture-related costs. One retrospective study, for example, found that $70 \%$ of fractures and $87 \%$ of costs were incurred by Americans who were 65 years and older (thus eligible for Medicare), and that inpatient stays and long-term care were the largest contributors to total osteoporosis costs [1]. In the 
US, the total direct cost of incident and prevalent osteoporosis-related fractures is projected to increase from $\$ 19$ billion in 2005 to $\$ 25.3$ billion in 2025 , with this growth largely driven by fracture incidence among Medicare-aged individuals [1]. In addition to this direct cost burden, osteoporosis-related fractures of all types also may result in lasting impairments to quality of life, mobility, social and physical function, and increased risk of mortality lasting up to 5 years after a vertebral fracture and up to 10 years after a hip fracture [6, 7].

Fracture risk assessment tools have been incorporated into clinical guidelines in an effort to identify individuals for osteoporosis management, including pharmacologic treatment to prevent fractures, untimely death, and to reduce osteoporosisrelated costs to patients and society [8]. FRAX®, the most widely available such tool, uses patient demographic and clinical characteristics to estimate fracture risk over a 10 -year time horizon. While this long-term risk perspective is valuable for identifying patients for osteoporosis therapy, these tools may only be used once for a given patient, an approach that does not acknowledge the increasing appreciation that fracture risk is not always linear $[9,10]$. For example, medical events such as stroke or myocardial infarction and the use of certain types of medications may have both immediate and lasting effects on patients' physical functioning, balance, or gait which, in turn, may increase the risk of falling, a significant fracture risk factor [11]. Coincident with this growing awareness of the dynamic nature of fracture risk, research identifying specific factors contributing to imminent risk of fractures (i.e., within the next $1-2$ years) is accumulating [10,12-15]. As this field of research expands, the data obtained may be used to determine an appropriate threshold of risk that is clinically meaningful (e.g., percent of patients expected to experience a fracture within the next year) and can be used as a basis for treatment recommendations.

Given the greater incidence of fracture and more significant clinical, functional, quality of life, and cost consequences in the elderly, the current study was designed to identify predictors of imminent risk of fracture in the US Medicare population.

\section{Methods}

This study was conducted with data from inpatient, outpatient, and prescription drug claims in the $20 \%$ Medicare database, which includes information for a random sample of beneficiaries covered by Medicare Parts A, B, and D. The Part A and Part B database contain data on patient enrollment, clinical utilization, and expenditures for inpatient and outpatient professional and facility-based care as well as skilled nursing facilities and hospice care. The Medicare Part D database contains details of prescription drug utilization and costs.
Medicare beneficiaries included in this analysis were aged $\geq$ 67 years on January 1, 2011 (index date). To ensure complete capture of data on important covariates in the period prior to the index date, study patients were continuously enrolled in Medicare Parts A, B, and D between January 1, 2009 and March 31, 2011, and individuals with participation in any health maintenance organization (Medicare Advantage) plan were excluded. No other coverage-type exclusions were made. To reduce the risk of misclassification and increase the likelihood that any observed fractures were related to osteoporosis, patients with evidence of malignant neoplasm (excluding melanoma) or Paget's disease of bone in the 12 months prior to the index date were also excluded.

All patients were required to have 24 months of continuous plan enrollment prior to the index date. Patients were followed for up to 24 months after the index date and the occurrence of incident osteoporotic fracture was assessed during 12- and 24month follow-up intervals. Patients who contributed data to each assessment interval were required to have continuous plan enrollment during that interval. These fractures were identified with a published algorithm designed for use with administrative claims data [16]. Fractures were indicated by the presence of either (1) at least one inpatient claim with a relevant International Classification of Diseases, Ninth Revision, Clinical Modification (ICD-9-CM) diagnosis code or a Common Procedure Terminology (CPT) fracture repair procedure code or (2) an outpatient claim with both a qualifying diagnosis code and a fracture-related procedure code. Fractures with major trauma codes (E-codes) recorded concurrently were excluded from analysis.

The pool of potential predictors of imminent fracture risk was based on the existing literature on fracture risk factors, including recent studies examining factors associated with imminent risk of fracture. Predictor variables considered in this study included demographics (age, gender, race), history of fracture, history of falls, comorbid conditions (osteoporosis, cardiovascular diseases, chronic obstructive pulmonary disorder [COPD], mood and anxiety disorders, polyinflammatory conditions [rheumatoid arthritis, ankylosing spondylitis, osteoarthritis]), variables that may be markers for frailty (use of durable medical equipment, ambulance/life support, difficulty walking, paralysis, weakness, podiatric care), and baseline osteoporosis medication use and use of medications associated with secondary osteoporosis and/or fall risk (corticosteroids, central nervous system medications, antihypertensives). With the exception of fracture history which was determined during 24 months prior to the index date, these variables were quantified during a 12-month pre-index period.

Multivariate Cox proportional hazards models were used to evaluate potential predictors of imminent risk of fracture, with separate models constructed to identify predictors of fracture risk in 12 months and 24 months of follow-up. In the initial analysis, the models included all potential predictors. 
Reduced, parsimonious models were obtained using the augmented backward elimination algorithm with a $10 \%$ change in estimate criterion required to retain a variable in the final model [17]. A risk-scoring point system based on the Sullivan methodology [18] was applied to convert the model results into risk scores. With this methodology, increasing numbers of points were assigned to increasing levels of risk (e.g., increasing age was associated with a greater number of points), and the totaled points correspond to an individual's predicted fracture probability during follow-up. All analyses were conducted using SAS® software, version 9.2 (SAS Institute Inc., Cary, NC).

\section{Results}

Baseline demographic, clinical, and healthcare utilization characteristics for the 1,780,451 individuals who met all study inclusion criteria are summarized in Table 1. The mean (standard deviation [SD]) age of patients in the study cohort was 77.7 years (7.5); $66.0 \%$ of patients were female and $85.2 \%$ of patients were white. In the 24 months prior to the index date, $8.3 \%$ of patients had experienced a fracture and $6.1 \%$ had a history of falls.

During the 12- and 24-month follow-up periods, 3.0\% and $5.4 \%$ of patients in the cohort had an incident osteoporotic fracture, respectively. The proportion of patients with an incident hip, vertebral or non-hip/non-vertebral fractures during the 24 months of follow-up were $1.4 \%, 1.6 \%$, and $2.3 \%$ respectively.

Factors most strongly associated with fractures in 12 months of follow-up included older age, female sex, white race, history of fracture, history of falls, and comorbidities (osteoporosis, cardiovascular disease, COPD, ankylosing spondylitis, depression, and anxiety/mood disorders) (Table 2). Other factors associated with imminent risk of fracture included ambulance/life support, difficulty walking, use of durable medical equipment, and diminished physical function. The findings were largely consistent for factors associated with the risk of fracture during 24 months of follow-up.

Table 3 shows the points that were assigned to each category of each of the factor evaluated as a fracture risk predictor with higher points indicating higher risk. Points differ for males and females in the study population and by follow-up time (12 months, 24 months). These points were used in the calculation of patient-level fracture risk scores; the distribution of scores in the study population is summarized in Supplemental Table 1. For both men and women, the distribution of patients by risk score was similar for the 12- and 24month follow-up periods. The majority (69\%) of men had 12month risk scores between 16 and 30 . Women tended to have higher risk scores, with $56 \%$ having 12 -month scores of 26 to 50 and nearly one-quarter having12-month scores of 50 or
Table 1 Distribution of selected demographic, clinical and other factors in the study cohort

\begin{tabular}{|c|c|}
\hline Characteristic & Mean (SD)/Percent \\
\hline Total patients & $1,780,451$ \\
\hline \multicolumn{2}{|l|}{ Demographics } \\
\hline Age in years, mean (SD) & $77.7(7.5)$ \\
\hline Male, percent & 34.0 \\
\hline White, percent & 85.2 \\
\hline \multicolumn{2}{|l|}{ Selected clinical characteristics, percent } \\
\hline Hospitalized & 18.9 \\
\hline History of fracture & 8.3 \\
\hline History of falls & 6.1 \\
\hline Osteoporosis & 5.5 \\
\hline Congestive heart failure & 9.1 \\
\hline Diabetes mellitus & 25.7 \\
\hline COPD & 12.5 \\
\hline Gastrointestinal disorders/toxicities & 6.5 \\
\hline Chronic kidney disease & 8.7 \\
\hline Anemia & 13.5 \\
\hline Thyroid disease & 12.1 \\
\hline Rheumatoid arthritis & 2.0 \\
\hline Osteoarthritis & 13.7 \\
\hline Depression & 6.5 \\
\hline Dementia & 7.4 \\
\hline Mood or anxiety disorders & 3.6 \\
\hline Ankylosing spondylitis & $<1$ \\
\hline \multicolumn{2}{|l|}{ Frailty markers, percent } \\
\hline Use of DME & 11.3 \\
\hline Ambulance/life support & 14.7 \\
\hline Difficulty walking & 15.4 \\
\hline Paralysis & 2.5 \\
\hline Weakness & 10.6 \\
\hline Podiatric care & 11.9 \\
\hline \multicolumn{2}{|l|}{ Mitigating factors, percent } \\
\hline Physical occupational therapy & 23.7 \\
\hline Nurse home services & 6.2 \\
\hline Home healthcare services & 10.7 \\
\hline \multicolumn{2}{|l|}{ Concomitant medications, percent } \\
\hline Osteoporosis medications $\mathrm{s}^{\mathrm{a}}$ & 15.0 \\
\hline Glucocorticoids & 26.5 \\
\hline Thyroxin & 19.4 \\
\hline Antihypertensives ${ }^{\mathrm{a}}$ & 71.2 \\
\hline CNS active medications ${ }^{\mathrm{a}}$ & 8.8 \\
\hline Heparin & 1.7 \\
\hline
\end{tabular}

CNS Central nervous system, $C O P D$ chronic obstructive pulmonary disease, $D M E$ durable medical equipment; $S D$ standard deviation

${ }^{a}$ Osteoporosis medications include: bisphosphonates, calcitonin, teriparatide, raloxifene, denosumab. Antihypertensives include beta blockers, calcium channel blockers, renin-angiotensin system antagonists, antiadrenergic/sympatholytics, etc. CNS active medications include tryclic antidepressants, monoamine oxidase inhibitors, antipsychotic agents, lithium 
Table 2 Factors associated with imminent risk of fracture in 12 and 24-month follow-ups

\begin{tabular}{|c|c|c|c|c|}
\hline \multirow[t]{2}{*}{ Factors } & \multicolumn{2}{|l|}{ 12-month risk } & \multicolumn{2}{|l|}{ 24-month risk } \\
\hline & Hazard ratio & $95 \% \mathrm{CI}$ & Hazard ratio & $95 \% \mathrm{CI}$ \\
\hline \multicolumn{5}{|l|}{ Demographic } \\
\hline \multicolumn{5}{|l|}{ Age in years } \\
\hline $67-69$ & Reference & & Reference & \\
\hline $70-74$ & 1.22 & $1.17-1.26$ & 1.22 & $1.19-1.26$ \\
\hline $75-79$ & 1.69 & $1.63-1.76$ & 1.73 & $1.68-1.77$ \\
\hline $80-84$ & 2.29 & $2.21-2.37$ & 2.38 & $2.32-2.44$ \\
\hline $85+$ & 3.12 & $3.01-3.23$ & 3.27 & $3.19-3.35$ \\
\hline Male & 0.55 & $0.54-0.56$ & 0.54 & $0.53-0.55$ \\
\hline \multicolumn{5}{|l|}{ Race } \\
\hline While & Reference & & & \\
\hline Black & 0.43 & $0.41-0.45$ & 0.42 & $0.41-0.44$ \\
\hline Hispanic & 0.70 & $0.66-0.75$ & 0.72 & $0.69-0.75$ \\
\hline Asian & 0.66 & $0.62-0.71$ & 0.66 & $0.63-0.69$ \\
\hline Other & 0.81 & $0.75-0.87$ & 0.80 & $0.76-0.85$ \\
\hline History of Fracture & 2.46 & $2.41-2.52$ & 2.21 & $2.17-2.25$ \\
\hline History of Falls & 1.18 & $1.14-1.21$ & 1.16 & $1.14-1.19$ \\
\hline \multicolumn{5}{|l|}{ Clinical conditions } \\
\hline Osteoporosis & 1.22 & $1.18-1.25$ & 1.21 & $1.18-1.24$ \\
\hline Cardiovascular disease & 1.11 & $1.09-1.13$ & 1.12 & $1.10-1.13$ \\
\hline COPD & 1.16 & $1.14-1.19$ & 1.17 & $1.15-1.19$ \\
\hline Ankylosing spondylitis & 1.52 & $1.36-1.70$ & 1.41 & $1.29-1.55$ \\
\hline Depression & 1.14 & $1.11-1.17$ & 1.13 & $1.11-1.16$ \\
\hline Mood or anxiety orders & 1.07 & $1.03-1.11$ & 1.10 & $1.07-1.13$ \\
\hline \multicolumn{5}{|l|}{ Frailty markers } \\
\hline Ambulance/life support & 1.16 & $1.13-1.19$ & 1.15 & $1.13-1.17$ \\
\hline Difficulty walking & 1.15 & $1.12-1.18$ & 1.14 & $1.12-1.16$ \\
\hline Use of DME & 1.12 & $1.09-1.14$ & 1.11 & $1.09-1.13$ \\
\hline \multicolumn{5}{|l|}{ Concomitant medications } \\
\hline Osteoporosis medications $\mathrm{s}^{\mathrm{a}}$ & 1.26 & $1.24-1.29$ & 1.27 & $1.25-1.29$ \\
\hline Glucocorticoids & 1.13 & $1.11-1.15$ & 1.13 & $1.12-1.15$ \\
\hline Heparin & 1.21 & $1.14-1.28$ & 1.16 & $1.11-1.21$ \\
\hline CNS active medications ${ }^{\mathrm{a}}$ & 1.13 & $1.10-1.16$ & 1.11 & $1.09-1.13$ \\
\hline
\end{tabular}

$C N S$ central nervous system, $C O P D$ chronic obstructive pulmonary disease, $D M E$ durable medical equipment

${ }^{a}$ Osteoporosis medications include bisphosphonates, calcitonin, teriparatide, raloxifene, denosumab. CNS active medications include tricyclic antidepressants, monoamine oxidase inhibitors, antipsychotic agents, lithium higher. A similar shift was observed in comparing 24-month risk scores for men and women. The probability of fracture during the 12- and 24-month follow-up periods is shown for males and females at each risk score level and is provided in Supplemental Table 2.

\section{Discussion}

In this analysis of administrative claims from the $20 \%$ Medicare sample, the factors most strongly associated with imminent (12- and 24-month) risk of fracture included older age, female sex, white race, and history of fractures within the previous year. These results contribute to the understanding of imminent fracture risk by quantifying the real-world effect of these specific risk factors in a large population of men and women enrolled in Medicare. Individuals who were aged 80 years or older had two to three times the risk of fracture over the next 12 to 24 months as did individuals under age 70 years. Similarly, a history of fracture within 24 months of the index date doubled the risk of subsequent fracture in the near-term (within the next 12 and 24 months), and females were more than $80 \%$ more likely than males to experience a fracture in that interval. Among the comorbidities assessed as 
Table 3 Points used in risk score calculation

\begin{tabular}{lllll}
\hline Variable & Categories & Male & \multicolumn{2}{l}{ Female } \\
\hline & One year & Two years & One year & Two years
\end{tabular}

Age

$\begin{array}{lllll}67-69 & 0 & 0 & 0 & 0 \\ 70-74 & 4 & 4 & 4 & 4 \\ 75-79 & 9 & 9 & 9 & 9 \\ 80-84 & 14 & 14 & 14 & 14 \\ 85+ & 25 & 25 & 25 & 25\end{array}$

White

$\begin{array}{lllll}\text { No } & 0 & 0 & 0 & 0 \\ \text { Yes } & 5 & 5 & 4 & 4\end{array}$

Black

$\begin{array}{lllll}\text { No } & 6 & 5 & 14 & 13 \\ \text { Yes } & 0 & 0 & 0 & 0\end{array}$

Hispanic

$\begin{array}{lllll}\text { No } & 1 & 0 & 2 & 1 \\ \text { Yes } & 0 & 1 & 0 & 0\end{array}$

Asian

$\begin{array}{lllll}\text { No } & 4 & 5 & 4 & 3\end{array}$

Yes $\quad$ (1)

Previous fracture

$\begin{array}{lllll}\text { No } & 0 & 0 & 0 & 0\end{array}$

Yes

19

16

18

Osteoporosis

No

Not a

Not a

Predictor

Yes

Not a Predictor

CV disease

No

Yes

0

3

$0 \quad 0$

COPD

No
Yes

Anemia

No
Yes

Gastrointestinal disorders and toxicities

No

$$
0
$$

5

0
5

5

Not a

Predictor

Yes
Not a
Predictor

No

Yes

Not a

Predictor

\section{No}

Yes

0

4

Not a

Predictor

5

4

3

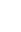

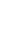

(1)


Table 3 (continued)

\begin{tabular}{|c|c|c|c|c|c|}
\hline Variable & Categories & Male & & Female & \\
\hline \multirow[t]{3}{*}{ Skin ulcer } & & Not a & Not a & Not a & \\
\hline & No & Predictor & Predictor & Predictor & 4 \\
\hline & Yes & & & & 0 \\
\hline \multirow[t]{3}{*}{ Difficulty walking } & & & & Not a & Not a \\
\hline & No & 0 & 0 & Predictor & Predictor \\
\hline & Yes & 5 & 5 & & \\
\hline \multirow[t]{3}{*}{ Use of DME } & & Not a & Not a & & \\
\hline & No & Predictor & Predictor & 0 & 0 \\
\hline & Yes & & & 3 & 2 \\
\hline \multirow{3}{*}{$\begin{array}{l}\text { Osteoporosis } \\
\text { medications }\end{array}$} & & & & & \\
\hline & No & 0 & 0 & 0 & 0 \\
\hline & Yes & 11 & 10 & 5 & 5 \\
\hline \multirow[t]{3}{*}{ Glucocorticoids } & & Not a & Not a & & \\
\hline & No & Predictor & Predictor & 0 & 0 \\
\hline & Yes & & & 3 & 3 \\
\hline
\end{tabular}

potential risk factors, codes for ankylosing spondylitis and osteoporosis were associated with the greatest increased risk ( $52 \%$ and $22 \%$, respectively). History of falls, diminished physical function (e.g., difficulty walking, weakness, paralysis as indicated by diagnosis and procedure codes), and use of particular types of services (e.g., ambulance/life support, durable medical equipment), which may suggest frailty, were associated with a 12 to $16 \%$ increase in the risk of fracture, while the use of osteoporosis medications and heparin was associated with $26 \%$ and $21 \%$ greater risk, respectively. It is likely that patients prescribed osteoporosis medications during the pre-index period were at higher risk for fracture relative to those not prescribed osteoporosis therapy. It was beyond the scope of the current study to evaluate medication adherence in these patients, but the literature indicates that non-adherence is a significant challenge among patients with osteoporosis, and suboptimal adherence can significantly reduce the therapeutic benefits that patients derive from these medications [19, 20].

These findings are consistent with previous studies of factors that influence imminent risk of fracture. A recent casecontrol study of US men and women aged 50 years and older with commercial and Medicare supplemental insurance reported that in patients with osteoporosis and no recent fracture, falls, older age, poorer health status, comorbidities (psychosis, Alzheimer's disease, central nervous system disease), and other potential fall risk factors were associated with increased risk of fracture in 12 and 24 months [12]. In an analysis of data obtained for Caucasian subjects in the Study of Osteoporotic Fractures (SOF) cohort, imminent risk of hip fracture was predicted by total hip T-score, non-vertebral fracture after age 50 years, and indicators of poor physical functioning. In this SOF population, age, total hip T-score, fracture after age 50 years, walking speed, Parkinson's disease or stroke, smoking, and prior falls were independent risk factors for imminent non-vertebral fractures [14].

Together, the results of these studies indicate an important overlap between factors that influence imminent risk of fracture and those that influence risk in the long term (10 years), including age, race, indicators of bone health (osteoporosis diagnosis, bone mineral density), and history of fracture. When focusing specifically on fracture risk within 1-2 years, however, it is important to note that there are additional risk factors and to understand the dynamic nature of these risk factors as medical events occur or physical functioning changes. For example, it is well known that prior fractures at any site increase the risk of subsequent fracture, independent of BMD, and generally accepted that half of all patients who have had an osteoporotic fracture will go on to experience a subsequent fracture [21-30]. The scientific evidence demonstrating this risk relationship is so significant that the International Osteoporosis Foundation (IOF) has designated the prevention of subsequent fractures (i.e., secondary prevention) as the single most important opportunity to improve osteoporosis care and impact the trend of rapidly increasing fracture-related costs worldwide [31]. Analysis of data from a recent, large (18,872 individuals, 510,265 person-years follow-up) population-based cohort in Reykjavik, Iceland, however, suggests that the level of risk associated with prior fracture varies with both time since fracture and patient age [13]. In general, risk was highest immediately after the first fracture, and although risk declined over time, it never reached the level seen in the general population. Specifically, in the first year after the first major osteoporotic fracture, the risk of subsequent fracture was 2.7 (95\% confidence interval: 2.4-3.0) times higher than the population risk. Ten years after the initial fracture, the risk ratio had fallen to $1.4(1.2-1.6)$, and risk 
remained elevated for at least 15 years. Interestingly, this pattern of risk reduction over time appeared to be age-dependent and most evident in patients older than 60 years. These results illustrate how varying the time horizon used for fracture risk prediction can lead to different conclusions about the importance of key risk factors as the effect of these factors varies with time and within the context of other risk factors.

There is a wealth of epidemiologic evidence demonstrating strong associations between falls and fractures in the elderly [11]. In addition, not only has history of falls been associated with an increased risk of fracture in the near-term, but also current and previous studies have shown that factors that increase the risk of falls (e.g., poor physical functioning, mobility impairments, use of psychoactive medications) appear to influence fracture risk $[12,14]$. These factors may also be quite dynamic, and changes in the patients fall history or fall-related risk profiles significantly impact their fracture risk as well.

In addition to identifying specific risk factors, the accumulating literature on imminent risk of fracture highlights the importance of ensuring that clinicians understand both the significance and dynamic nature of key risk factors for imminent risk of fracture. Routine monitoring for recent fractures, falls, or changes in physical functioning or mobility, incident diagnosis of conditions that affect coordination or balance, and the timely initiation of certain pharmacologic therapies may have the potential to reduce a patient's imminent risk of fracture. The therapeutic benefit associated with early intervention following an initial fracture is expected to be significant in the elderly, and it seems reasonable to assume that the ability to routinely identify other significant predictors of imminent risk will provide an opportunity to more effectively manage at-risk patients [13]. Ensuring appropriate prescribing and use of osteoporosis medications may be challenging in the Medicare population, including among patients who have already sustained an osteoporotic fracture. One recent study, for example, found that only $30 \%$ of Medicare-enrolled patients $(N=145,185)$ who sustained a fracture between 2008 and 2011 filled a prescription for an osteoporosis medication during the 12 months post-fracture [32].

Our study has a number of strengths which enhance the generalizability and rigor of the results. The primary strength of our study is the availability of detailed clinical data for a large sample of elderly individuals, which should effectively generalize to the Medicare population overall since the study population was drawn from the $20 \%$ Medicare sample. Although osteoporosis and osteoporosis-related fractures disproportionately affect postmenopausal women, the inclusion of men in our study provides a more complete understanding of factors that influence imminent risk of fracture than a single-sex study would provide. To our knowledge, only one other study of US data has included males in evaluating predictors of imminent risk, and that study which included commercially insured individuals and Medicare enrollees aged 50 years and older did not identify sex as a significant risk predictor [12]. Access to detailed clinical and demographic data over 24 months of pre- and post-index periods allowed us to evaluate the role of a diverse set of potential risk factors on incident fracture in 12 and 24 months follow-up intervals. That said, some potential risk factors documented in previous studies (e.g., specific measures of mobility or physical functioning [grip strength, walking speed]) are not evaluable in administrative claims data. We also note that only outpatient medication fills were included, and medication use may have changed for individual patients during follow-up. However, these predictors were not defined in a time-varying manner in the models, so the impact of such changes is not captured in these results. Although the presence/absence of historical fracture was noted in the study database, our ability to characterize these prior fractures was limited since details on the timing and site of those prior fractures were not available. In addition, since it is challenging to identify incident fractures (our primary study outcome) in administrative claims data, we used a previously published claims-based algorithm [16] . This approach likely reduced but may not have eliminated all potential misclassification of this outcome. Finally, although patients may have died during follow-up, death was not considered as a competing risk in the multivariate models. Future studies may be able to not only build upon the current study but also address important limitations by including detailed data on the recency of prior fracture and treatment adherence, as well as considering death as a competing risk.

Our study shows that advancing age, female sex, recent prior fracture and falls, and specific comorbidities and medications were factors contributing to imminent risk of fracture among Medicare-aged individuals. While there is overlap between risk factors that shape imminent and long-term fracture risk, the dynamic nature of certain risk factors is particularly important for accurately estimating imminent risk and making appropriate decisions regarding treatment. For example, elderly patients who initiate osteoporosis medications soon after an initial fracture when the increased risk of subsequent fracture is highest will have the greatest opportunity to derive critical therapeutic benefit and potentially avoid a second fracture. Health care providers may also inform their choice of therapy with an assessment of imminent risk in a given patient, and, for example, may prescribe a bone-forming agent for rapid fracture risk reduction prior to antiresorptive therapy for a high-risk patient. Similarly, clinicians who routinely monitor their patients for changes in key imminent risk factors including recent falls or changes in fall risk factors, medical events (e.g., stroke), comorbidities, or medication regimens may have an opportunity to identify patients to receive therapy, change therapy, or improve their treatment compliance as patients' risk of fracture increases. The timing of routine assessment must be considered, but clinicians may consider annual 
assessments for patients of average risk and more frequent assessment for patients with multiple risk factors or rapidly changing health. Clinician awareness of these risk factors and their dynamic nature may lead to improved osteoporosis care for elderly patients.

Acknowledgments This study was supported by Amgen Inc.; Thousand Oaks, CA. Robert Dawson of Cactus Communications provided graphics support, and Sally Wade of Wade Outcomes Research and Consulting provided writing support.

Funding information Amgen Inc. and UCB Pharma provided funding for this study.

\section{Compliance with ethical standards}

Conflict of interest $\mathrm{AY}, \mathrm{DC}, \mathrm{BC}$, and $\mathrm{RB}$ are/were Amgen employees and stockholders. YH has no disclosures.

Open Access This article is licensed under a Creative Commons Attribution 4.0 International License, which permits use, sharing, adaptation, distribution and reproduction in any medium or format, as long as you give appropriate credit to the original author(s) and the source, provide a link to the Creative Commons licence, and indicate if changes were made. The images or other third party material in this article are included in the article's Creative Commons licence, unless indicated otherwise in a credit line to the material. If material is not included in the article's Creative Commons licence and your intended use is not permitted by statutory regulation or exceeds the permitted use, you will need to obtain permission directly from the copyright holder. To view a copy of this licence, visit http://creativecommons.org/licenses/by/4.0/.

\section{References}

1. Burge R, Dawson-Hughes B, Solomon DH, Wong JB, King A, Tosteson A (2007) Incidence and economic burden of osteoporosis-related fractures in the United States, 2005-2025. J. Bone Miner. Res. 22(3):465-475. https://doi.org/10.1359/jbmr. 061113

2. Strom O, Borgstrom F, Kanis JA, Compston J, Cooper C, McCloskey EV, Jonsson B (2011) Osteoporosis: burden, health care provision and opportunities in the EU: a report prepared in collaboration with the International Osteoporosis Foundation (IOF) and the European Federation of Pharmaceutical Industry Associations (EFPIA). Arch Osteoporos 6:59-155. https://doi.org/ 10.1007/s11657-011-0060-1

3. Wade SW, Strader C, Fitzpatrick LA, Anthony MS (2012) Sex- and age-specific incidence of non-traumatic fractures in selected industrialized countries. Arch Osteoporos 7:219-227. https://doi.org/10. 1007/s11657-012-0100-5

4. Liu SK, Munson JC, Bell JE, Zaha RL, Mecchella JN, Tosteson AN, Morden NE (2013) Quality of osteoporosis care of older Medicare recipients with fragility fractures: 2006 to 2010. J Am Geriatr Soc 61(11):1855-1862. https://doi.org/10.1111/jgs.12507

5. Rousculp MD, Long SR, Wang S, Schoenfeld MJ, Meadows ES (2007) Economic burden of osteoporosis-related fractures in Medicaid. Value Health 10(2):144-152. https://doi.org/10.1111/j. 1524-4733.2006.00161.x

6. Bliuc D, Nguyen ND, Nguyen TV, Eisman JA, Center JR (2013) Compound risk of high mortality following osteoporotic fracture and refracture in elderly women and men. J. Bone Miner. Res. 28(11):2317-2324. https://doi.org/10.1002/jbmr.1968

7. Ioannidis G, Papaioannou A, Hopman WM, Akhtar-Danesh N, Anastassiades T, Pickard L, Kennedy CC, Prior JC, Olszynski WP, Davison KS, Goltzman D, Thabane L, Gafni A, Papadimitropoulos EA, Brown JP, Josse RG, Hanley DA, Adachi JD (2009) Relation between fractures and mortality: results from the Canadian Multicentre Osteoporosis Study. CMAJ 181(5):265271. https://doi.org/10.1503/cmaj.081720

8. FRAX fracture risk assessment tool. https://www.sheffield.ac.uk/ FRAX/. Accessed 7 Oct 2017

9. Pinedo-Villanueva R, Charokopou M, Toth E, Donnelly K, Cooper C, Prieto-Alhambra D, Libanati C, Javaid MK (2019) Imminent fracture risk assessments in the UK FLS setting: implications and challenges. Arch Osteoporos 14(1):12. https://doi.org/10.1007/ s11657-019-0569-2

10. Roux C, Briot K (2017) Imminent fracture risk. Osteoporos Int 28(6):1765-1769. https://doi.org/10.1007/s00198-017-3976-5

11. Masud T, Binkley N, Boonen S, Hannan MT, Members FPDC (2011) Official positions for FRAX(R) clinical regarding falls and frailty: can falls and frailty be used in FRAX(R)? From Joint Official Positions Development Conference of the International Society for Clinical Densitometry and International Osteoporosis Foundation on FRAX(R). J Clin Densitom 14(3):194-204. https://doi.org/10.1016/j.jocd.2011.05.010

12. Bonafede M, Shi N, Barron R, Li X, Crittenden DB, Chandler D (2016) Predicting imminent risk for fracture in patients aged 50 or older with osteoporosis using US claims data. Arch Osteoporos 11(1):26. https://doi.org/10.1007/s11657-016-0280-5

13. Johansson H, Siggeirsdottir K, Harvey NC, Oden A, Gudnason V, McCloskey E, Sigurdsson G, Kanis JA (2017) Imminent risk of fracture after fracture. Osteoporos Int 28(3):775-780. https://doi. org/10.1007/s00198-016-3868-0

14. Weycker D, Edelsberg J, Barron R, Atwood M, Oster G, Crittenden DB, Grauer A (2017) Predictors of near-term fracture in osteoporotic women aged $>/=65$ years, based on data from the study of osteoporotic fractures. Osteoporos Int 28:2565-2571. https://doi. org/10.1007/s00198-017-4103-3

15. Balasubramanian A, Zhang J, Chen L, Wenkert D, Daigle SG, Grauer A, Curtis JR (2019) Risk of subsequent fracture after prior fracture among older women. Osteoporos Int 30(1):79-92

16. Song X, Shi N, Badamgarav E, Kallich J, Varker H, Lenhart G, Curtis JR (2011) Cost burden of second fracture in the US health system. Bone 48(4):828-836. https://doi.org/10.1016/j.bone.2010. 12.021

17. Dunkler D, Plischke M, Leffondre K, Heinze G (2014) Augmented backward elimination: a pragmatic and purposeful way to develop statistical models. PLoS One 9(11):e113677. https://doi.org/10. 1371/journal.pone. 0113677

18. Sullivan LM, Massaro JM, D'Agostino RB Sr (2004) Presentation of multivariate data for clinical use: the Framingham study risk score functions. Stat Med 23(10):1631-1660. https://doi.org/10. 1002/sim. 1742

19. Siris ES, Selby PL, Saag KG, Borgstrom F, Herings RM, Silverman SL (2009) Impact of osteoporosis treatment adherence on fracture rates in North America and Europe. Am J Med 122(2 Suppl):S3S13. https://doi.org/10.1016/j.amjmed.2008.12.002

20. Diez-Perez A, Hooven FH, Adachi JD, Adami S, Anderson FA, Boonen S, Chapurlat R, Compston JE, Cooper C, Delmas P, Greenspan SL, Lacroix AZ, Lindsay R, Netelenbos JC, Pfeilschifter J, Roux C, Saag KG, Sambrook P, Silverman S, Siris ES, Watts NB, Nika G, Gehlbach SH (2011) Regional differences in treatment for osteoporosis. The Global Longitudinal Study of Osteoporosis in Women (GLOW). Bone 49(3):493-498. https:// doi.org/10.1016/j.bone.2011.05.007 
21. Delmas PD, Genant HK, Crans GG, Stock JL, Wong M, Siris E, Adachi JD (2003) Severity of prevalent vertebral fractures and the risk of subsequent vertebral and nonvertebral fractures: results from the MORE trial. Bone 33(4):522-532

22. FitzGerald G, Boonen S, Compston JE, Pfeilschifter J, LaCroix AZ, Hosmer DW Jr, Hooven FH, Gehlbach SH, Investigators G (2012) Differing risk profiles for individual fracture sites: evidence from the Global Longitudinal Study of Osteoporosis in Women (GLOW). J. Bone Miner. Res. 27(9):1907-1915. https://doi.org/ 10.1002/jbmr. 1652

23. Giangregorio LM, Leslie WD, Manitoba Bone Density P (2010) Time since prior fracture is a risk modifier for 10-year osteoporotic fractures. J. Bone Miner. Res. 25(6):1400-1405. https://doi.org/10. $1002 / \mathrm{jbmr} .35$

24. Haentjens P, Autier P, Collins J, Velkeniers B, Vanderschueren D, Boonen S (2003) Colles fracture, spine fracture, and subsequent risk of hip fracture in men and women. A meta-analysis. J Bone Joint Surg Am 85-A(10):1936-1943

25. Johnell O, Kanis JA, Oden A, Sernbo I, Redlund-Johnell I, Petterson C, De Laet C, Jonsson B (2004) Fracture risk following an osteoporotic fracture. Osteoporos Int 15(3):175-179. https://doi. org/10.1007/s00198-003-1514-0

26. Kanis JA, Johnell O, De Laet C, Johansson H, Oden A, Delmas P, Eisman J, Fujiwara S, Garnero P, Kroger H, McCloskey EV, Mellstrom D, Melton LJ, Pols H, Reeve J, Silman A, Tenenhouse A (2004) A meta-analysis of previous fracture and subsequent fracture risk. Bone 35(2):375-382. https://doi.org/10.1016/j.bone. 2004.03.024

27. Klotzbuecher CM, Ross PD, Landsman PB, Abbott TA 3rd, Berger M (2000) Patients with prior fractures have an increased risk of future fractures: a summary of the literature and statistical synthesis. J. Bone Miner. Res. 15(4):721-739. https://doi.org/10.1359/jbmr. 2000.15.4.721

28. Roux C, Fechtenbaum J, Kolta S, Briot K, Girard M (2007) Mild prevalent and incident vertebral fractures are risk factors for new fractures. Osteoporos Int 18(12):1617-1624. https://doi.org/10. 1007/s00198-007-0413-1

29. van Staa TP, Leufkens HG, Cooper C (2002) Does a fracture at one site predict later fractures at other sites? A British cohort study. Osteoporos Int 13(8):624-629. https://doi.org/10.1007/ s001980200084

30. Wustrack R, Seeman E, Bucci-Rechtweg C, Burch S, Palermo L, Black DM (2012) Predictors of new and severe vertebral fractures: results from the HORIZON Pivotal Fracture Trial. Osteoporos Int 23(1):53-58. https://doi.org/10.1007/s00198-011-1664-4

31. Akesson K, Marsh D, Mitchell PJ, McLellan AR, Stenmark J, Pierroz DD, Kyer C, Cooper C, Group IOFFW (2013) Capture the fracture: a best practice framework and global campaign to break the fragility fracture cycle. Osteoporos Int 24(8):21352152. https://doi.org/10.1007/s00198-013-2348-z

32. Yusuf AA, Matlon TJ, Grauer A, Barron R, Chandler D, Peng Y (2016) Utilization of osteoporosis medication after a fragility fracture among elderly Medicare beneficiaries. Arch Osteoporos 11(1): 31. https://doi.org/10.1007/s11657-016-0285-0

Publisher's note Springer Nature remains neutral with regard to jurisdictional claims in published maps and institutional affiliations. 